\title{
Alinhamento do portfólio de projetos à estratégia das organizações: um estudo exploratório quantitativo
}

\section{Strategic alignment of project portfolio: a quantitative exploratory study}

\author{
Renan Mastrange Guedes \\ Mestrando em Administração de Empresas pela Faculdade de Economia, Administração e \\ Contabilidade da Universidade de São Paulo/ Brasil \\ Pós-Graduado em Administração pela Harvard Business School \\ Bacharel em Administração de Empresas pela Faculdade de Economia, Administração e Contabilidade \\ da Universidade de São Paulo/ Brasil \\ renan.guedes@usp.br \\ Fernando Fonseca \\ Mestrando em Administração pela Faculdade de Economia, Administração e Contabilidade da \\ Universidade de São Paulo/ Brasil \\ Bacharel em Direito pela Pontifícia Universidade Católica do Paraná/Brasil \\ Engenheiro mecânico pela Universidade Federal do Paraná/Brasil \\ fernandof@usp.br
}

Karine Lima de Carvalho Metre e doutoranda em Engenharia pela Escola Politécnica da Universidade de São Paulo/Brasil Bacharel em Ciências Econômicas pela Universidade Estadual Paulista/Brasil karine.carvalho@usp.br

Antônio Cesar Amaru Maximiano Professor associado Livre docente, doutor, mestre e bacharel em Administração pela Faculdade de Economia, Administração e Contabilidade da Universidade de São Paulo/ Brasil maximin@usp.br

Marilson Alves Gonçalves Professor associado Livre docente, doutor, mestre e bacharel em Administração pela da Faculdade de Economia, Administração e Contabilidade da Universidade de São Paulo/ Brasil marilson@usp.br

Editor Científico Responsável Prof ${ }^{a}$. Dr ${ }^{a}$. Simone Fernandes Queiroz Departamento de Administração da Pontifícia Universidade Católica de Minas Gerais/Brasil

Submissão: $14 / 02 / 2011$

Aprovação: 21/11/2011

\section{Resumo}

Este trabalho apresenta os resultados de um estudo quantitativo, de natureza empíricoexploratória, sobre a percepção da importância das práticas e estruturas que promovem o alinhamento dos projetos com a estratégia nas organizações. O estudo foi realizado por meio da aplicação de um questionário eletrônico a profissionais envolvidos em projetos. A revisão da literatura que sustenta o estudo procurou sintetizar e organizar as principais teorias e modelos propostos a respeito desse tema. 
Palavras-chave: Administração Estratégica. Gerenciamento de Projetos. Gerenciamento de Portfólio de Projeto. Alinhamento Estratégico.

\section{Abstract}

This paper presents the results of an empiric-exploratory quantitative study on the relevance of practices and structures that leverage the alignment of project portfolio and corporate strategy. This research gathered the perception of project stakeholders by websurveying their perceptions. The literature review was aimed at organizing and synthesizing the main proposed models and theories on the subject.
\end{abstract}

Key-Words: Strategic Management. Project Management. Project Portfolio Management. Strategic Alignment. 


\section{INTRODUÇÃO}

Resumidamente, a gestão do portfólio de projetos consiste em tomar decisões sobre quais projetos executar e que recursos usar para executá-los (ARCHIBALD, 2004). A implementação da estratégia, por meio da gestão competente do portfólio, é um dos fatores críticos para construção e manutenção de vantagens competitivas para as organizações (SHENHAR, 1999). Esse tema também é debatido por Kathuria, Joshi e Porth (2007), Artto e Dietrich (2004), Jamieson e Morris (2004), Srivannaboon e Milosevic (2004), Dietrich e Lehtonen (2005) e Srivannaboon (2006).

Pfeffer e Sutton (2000), Bossidy, Charan e Burck (2002), Hrebiniak (2005) e Govindarajan e Trimble (2010) discutem o alinhamento estratégico dos projetos por meio de um processo de gestão de portfólio. Já Cooper, Edgett e Kleinschmidt (2001; 2001b), Miller (2002), Kendall e Rollins (2003), Callahan e Brooks (2004), Martinsuo e Lehtonen (2007), PMI (2008), IPMA (2006) e OGC (2008) buscam identificar processos e práticas de maneira normativa, propondo modelos de alinhamento estratégico e gerenciamento do portfólio de projetos.

Segundo Mintzberg, Ahlstrand e Lampel. (2000), a concepção da administração estratégica como um sistema fechado, normativo e cíclico pode ser encontrada nas escolas prescritivas como a do design, do planejamento e do posicionamento, como, por exemplo, é proposto no Balanced Scorecard de Kaplan e Norton (1992; 1996; 2008). No entanto, para Mintzberg (1994) e Collins (2001), seria impróprio entender a estratégia como um processo formal, cíclico e fechado. Ainda Mintzberg, Ahlstrand e Lampel (2000) apontam a existência das escolas descritivas, tais como a empreendedora, a cognitiva, a de aprendizado, a do poder, a cultural e a ambiental, ou mesmo, a escola da configuração, que sugerem uma estratégia que é emergente mais da cultura e aprendizagem do que do processo de planejamento.

Assim, o objetivo desta pesquisa foi investigar a percepção da importância das práticas e estruturas que promovem o alinhamento dos projetos com a estratégia nas organizações, bem como discutir a execução da estratégia por meio do portfólio de projetos oficiais e extraoficiais (BLICHFELDT; ESKEROD, 2008), que, respectivamente, representam estratégias deliberadas e emergentes. Dando cumprimento a esse propósito, 
realizou-se um estudo empírico com stakeholders de projetos para coletar sua percepção sobre o tema.

O artigo foi estruturado em cinco seções, incluindo esta introdução. A segunda seção corresponde à revisão da literatura, em que são apresentados os aspectos discutidos pela literatura de gestão de projetos. A terceira seção corresponde à metodologia de pesquisa. $\mathrm{Na}$ quarta seção, os resultados obtidos são apresentados e analisados. Na quinta e última seção, são expostas as considerações finais dos autores. 


\section{REFERENCIAL TEÓRICO}

A definição de projeto como empreendimento com objetivo definido e sujeito a restrições de prazo e custo é considerada um construto operacional e normativo orientado para a eficiência. Essa definição vem evoluindo para incorporar perspectivas que levem em conta outros critérios de desempenho. Quando o interesse é a geração de valor por meio de projetos, em vez da eficiência, uma abordagem estratégica dessa disciplina se torna necessária (JUGDEV; THOMAS; DELISLE, 2001). Isso é particularmente verdadeiro no caso das empresas orientadas para projetos (project oriented businesses), que baseiam seus negócios na venda de produtos e serviços sob encomenda. (ARCHIBALD, 2004; RAD; RAGHAVAN, 2000; PINTO, 2002).

Segundo Shenhar e Dvir (2010), a dimensão estratégica enfatiza a eficácia na geração de vantagens competitivas por meio dos projetos: satisfação do cliente, colaboração, eficácia organizacional e compartilhamento de conhecimento, bem como outros itens necessários para vencer a concorrência. Além da dimensão estratégica, é preciso considerar a dimensão tática em que os projetos apoiam a implementação bem-sucedida da estratégia. Uma visão sistêmica dos projetos, dessa forma, compreende os três níveis ou dimensões: estratégia, tática e operacional (QUADRO 1).

\section{Quadro 1 - Amplitudes da definição de projeto}

\begin{tabular}{|l|l|}
\hline Amplitude & \multicolumn{1}{c|}{ Definição } \\
\hline Operacional & $\begin{array}{l}\text { "Um projeto é um esforço temporário, empreendido para criar um produto, serviço ou resultado } \\
\text { único" (PMI, 2008, p. 5). }\end{array}$ \\
\hline Tática & $\begin{array}{l}\text { "[...] um projeto pode ser definido por uma série de atividades e tarefas que têm o resultado } \\
\text { específico que é entregue dentro de certas especificações, possui data início e término, possui } \\
\text { em muitos casos limitações de fundos e custos, consome recursos materiais e humanos e são } \\
\text { multifuncionais" (KERZNER, 2009, p. 2). } \\
\text { "Um projeto é uma organização temporária, criada pela organização principal, para realizar um } \\
\text { empreendimento em seu benefício" (ANDERSEN, 2008, p. 10). }\end{array}$ \\
\hline \multirow{5}{*}{ Estratégica } \\
& $\begin{array}{l}\text { "Projetos são os motores que impulsionam inovações de ideias à comercialização. [...] os } \\
\text { propulsores que fazem com que as organizações sejam melhores, mais fortes e mais eficientes } \\
{[\ldots] \text { definimos um projeto como sendo uma organização temporária e o processo estabelecido }} \\
\text { para alcançar uma meta específica sob as restrições de tempo, orçamento e outros recursos" } \\
\text { (SHENHAR;DVIR, 2010, p. 17). } \\
\text { Projetos abordam "a mudança, procurando adaptar a organização à evolução de seu ambiente, } \\
\text { pelo reforço de sua coesão interna" (BOUTINET, 2006, p. 48). } \\
\text { "Uma forma de a organização movimentar sua estratégia é pela criação de determinados } \\
\text { projetos" (ANDERSEN, 2008, p. 66). }\end{array}$ \\
\hline
\end{tabular}
Fonte: Adaptado de ANSELMO e MAXIMIANO, 2010. 
No nível estratégico, as organizações tomam decisões sobre quais projetos executar e que recursos usar para executá-los (ARCHIBALD, 2004). Para que a escolha assegure o alinhamento dos projetos com a estratégia organizacional, é necessário usar o conceito e as ferramentas da gestão de portfólios.

A implementação da estratégia por meio da gestão competente da carteira de projetos corporativos é um dos fatores críticos para o sucesso no longo prazo e para a construção de vantagens competitivas sustentáveis. Evidentemente, diversos modelos de alinhamento estratégico da organização (PRIETO et al., 2009) procuraram explorar essa questão. No entanto este trabalho procura avançar na análise dessa questão, sob o prisma da gestão do portfólio de projetos das organizações.

A estratégia de uma organização compreende tanto os objetivos, as políticas e as iniciativas deliberadas, que são formais e explícitas, quanto as emergentes, que são implementadas independentemente de qualquer planejamento (MINTZBERG, 1994). O mesmo ocorre com os projetos - há os oficiais e os extraoficiais, todos compondo o portfólio dos projetos que a organização deve gerenciar (BLICHFELDT; ESKEROD, 2008). Essa convivência entre os projetos oficiais e extraoficiais reforça a necessidade do alinhamento dos projetos com estratégia.

$\mathrm{O}$ alinhamento dos projetos à estratégia da organização é amplamente discutido em Shenhar (1999), Kathuria, Joshi e Porth. (2007), Artto e Dietrich (2004), Jamieson e Morris (2004), Srivannaboon e Milosevic (2004), Dietrich e Lehtonen (2005) e Srivannaboon (2006). O OGC (Office of Government Commerce) buscou elaborar um modelo normativo que ilustra de maneira bastante razoável a interação entre o planejamento estratégico e a gestão do portfólio que endossa essa discussão (FIG. 1).

Figura 1 - Proposta de processo de planejamento estratégico e alinhamento do portfólio 


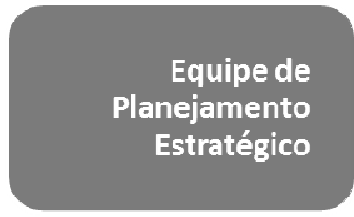

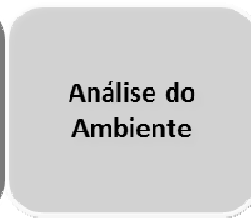

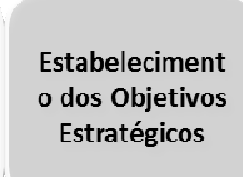

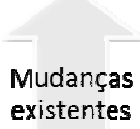

Estratégicos

existentes

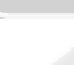

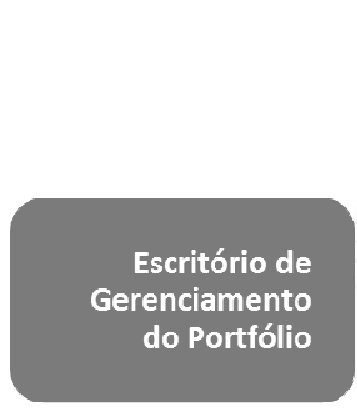

$$
\begin{gathered}
\text { Objetivos } \\
\text { estratégicos }
\end{gathered}
$$
Balanceamento
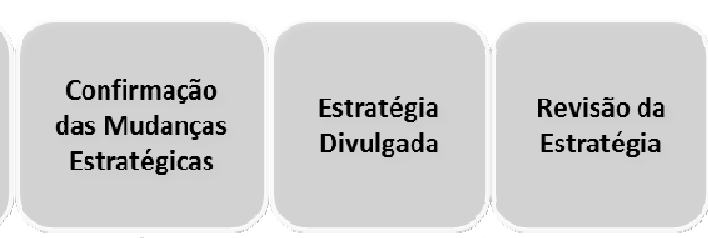

Categorização, Priorizaçãoe
Informaçőes Gerenclals do Portfólio \& Revisões Periódicas

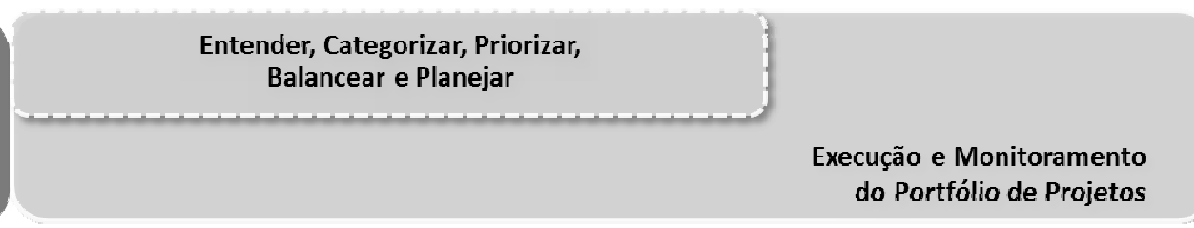

Fonte: Adaptado de OGC, 2008.

Diversos autores têm proposto modelos para atender a essa necessidade, tais como Cooper Edgett e Kleinschmidt (2001; 2001b), Miller (2002), Kendall e Rollins (2003), Callahan e Brooks (2004), Martinsuo e Lehtonen (2007). Há também os modelos normativos divulgados pelo PMI (2008), IPMA (2006) e OGC (2008), que objetivaram prescrever um conjunto de ferramentas e técnicas para os processos de identificação, categorização, avaliação, seleção, priorização, balanceamento, autorização, reporte e revisão, bem como controle da mudança do portfólio de projetos corporativos. Procurou-se sintetizar essas contribuições no Quadro 2.

No entanto, embora gerenciem seus portfólios de projetos segundo os preceitos da PPM - Project Portfolio Management, as empresas enfrentam problemas em relação ao conjunto de projetos atrasados, à concorrência por recursos, ao estresse e à falta de uma visão ampla. Segundo Blichfeldt e Eskerod (2008), a razão-chave pela qual as organizações não realizam bem a PPM é, em geral, essa gestão enfocar somente uma pequena parte do conjunto de projetos da organização: os projetos que são relevantes o suficiente para terem sido submetidos à avaliação e autorização da alta administração são denominados projetos oficiais. Ao mesmo tempo, projetos extraoficiais emergem e, sem serem submetidos à análise e priorização da alta administração, consomem os recursos que foram aprovados para os projetos constantes no portfólio oficial das empresas. Ao estudar a gestão do portfólio de projetos (e especialmente, a relação entre PPM e o desempenho dos projetos), é mais representativo levar em consideração o conjunto completo de projetos das organizações, sejam eles oficiais ou extraoficiais. Muitos projetos de pequena escala são iniciados, perseguidos e finalizados sob total desconhecimento da alta administração. Duas soluções Revista Economia \& Gestão - v. 11, n. 27, set./dez. 2011. 
parecem óbvias para esse problema: abranger todos os projetos, sem exceção, na PPM; e alocar mais recursos para um pulmão de recursos flexivelmente controlados para que os projetos extraoficiais avancem. (BLICHFELDT; ESKEROD, 2008).

Blichfeldt e Eskerod (2008) sugerem que procurar abranger todos os projetos na PPM tem algumas implicações a serem consideradas, tais como: (a) a alta administração tem capacidade limitada (cognitivamente, bem como em termos de tempo) para aplicar PPM a todos os projetos; (b) pode ser difícil identificar e estimar as atividades nos projetos extraoficiais e, ainda mais, realizar um detalhamento da alocação e necessidade de recursos para esses projetos; (c) a carga de trabalho e custo associados a identificar e administrar pequenos projetos pode ser muito alta e ter má relação de custo-benefício; (d) e a burocracia pode gerar menor flexibilidade e liberdade para projetos independentes ou mesmo individuais.

Alocar mais recursos para um pulmão de recursos controlado flexivelmente para que os projetos extraoficiais avancem pode trazer consequências como: (a) o trabalho rotineiro pode atrapalhar a execução tanto dos projetos oficiais como dos extraoficiais; (b) quando há prazos curtos em um projeto em específico, parece ser mais salutar focar os recursos neste projeto em vez de espalhá-los por diversos projetos; (c) essa estratégia pode depender de um alto nível de confiança nos funcionários; (d) a implementação dessa estratégia pode requerer que os gestores definam onde estaria a fronteira entre os projetos oficiais e extraoficiais; (e) e pode ser problemático não submeter os projetos extraoficiais há algum tipo de avaliação e aprovação. (BLICHFELDT e ESKEROD, 2008). 
Quadro 2 - Processos de gerenciamento do portfólio de projetos

\begin{tabular}{|c|c|c|c|c|c|c|c|c|c|c|c|}
\hline \multicolumn{3}{|c|}{ Grupos de Processo e Processos } & \multirow[t]{2}{*}{$\begin{array}{l}\text { Cooper et } \\
\text { al. }(2001 b)\end{array}$} & \multirow{2}{*}{$\begin{array}{l}\text { Miller } \\
\text { (2002) }\end{array}$} & \multirow{2}{*}{$\begin{array}{c}\text { Kendal e } \\
\text { Rollins } \\
(\mathbf{2 0 0 3 )}\end{array}$} & \multirow{2}{*}{$\begin{array}{c}\text { Callahan e } \\
\text { Brooks } \\
(\mathbf{2 0 0 4 )}\end{array}$} & \multirow{2}{*}{$\begin{array}{l}\text { Levine } \\
(2005)\end{array}$} & \multirow{2}{*}{$\begin{array}{c}\text { Martisuo e } \\
\text { Lehtonen } \\
\text { (2007) }\end{array}$} & \multirow{2}{*}{$\begin{array}{c}\text { PMI (2008) } \\
\mathrm{X}\end{array}$} & \multirow{2}{*}{$\begin{array}{l}\text { IPMA } \\
(\mathbf{2 0 0 6 )}\end{array}$} & \multirow{2}{*}{$\begin{array}{l}\text { OGC } \\
(2008)\end{array}$} \\
\hline \multirow{3}{*}{\multicolumn{2}{|c|}{$\begin{array}{l}\text { Adm. } \\
\text { Estratégica }\end{array}$}} & Missão e Visão & & & & & & & & & \\
\hline & & Planejamento Estratégico & & & & & & & $\mathrm{X}$ & & $\mathrm{X}$ \\
\hline & & $\begin{array}{l}\text { Objetivos } \\
\text { Estratégicos e Indicadores }\end{array}$ & & & & & & & $\mathrm{X}$ & $\mathrm{X}$ & $\mathrm{X}$ \\
\hline \multirow{7}{*}{ 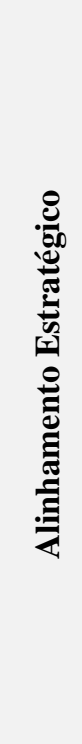 } & \multirow{5}{*}{ 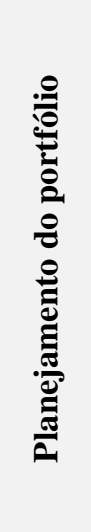 } & $\begin{array}{l}\text { Identificação de } \\
\text { componentes }\end{array}$ & & $\mathrm{X}$ & & & & & $\mathrm{X}$ & $\mathrm{X}$ & $\mathrm{X}$ \\
\hline & & $\begin{array}{l}\text { Categorização de } \\
\text { componentes }\end{array}$ & & $\mathrm{X}$ & & & & & $\mathrm{X}$ & & $X$ \\
\hline & & Avaliação de componentes & $\mathrm{X}$ & $\mathrm{X}$ & $X$ & $X$ & $\mathrm{X}$ & $\mathrm{X}$ & $\mathrm{X}$ & $\mathrm{X}$ & \\
\hline & & Seleção de componentes & $\mathrm{X}$ & $\mathrm{X}$ & $\mathrm{X}$ & $\mathrm{X}$ & $X$ & $\mathrm{X}$ & $\mathrm{X}$ & $X$ & \\
\hline & & $\begin{array}{l}\text { Priorização de } \\
\text { componentes }\end{array}$ & $\mathrm{X}$ & $\mathrm{X}$ & $\mathrm{X}$ & & $\mathrm{X}$ & $\mathrm{X}$ & $\mathrm{X}$ & $X$ & $X$ \\
\hline & \multirow{2}{*}{ 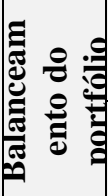 } & $\begin{array}{l}\text { Identificação dos riscos do } \\
\text { portfólio }\end{array}$ & & & & & & & $\mathrm{X}$ & & \\
\hline & & $\begin{array}{l}\text { Análise dos riscos do } \\
\text { portfólio }\end{array}$ & & & & & & & $X$ & & \\
\hline
\end{tabular}


PUC Minas

E\&G - REVISTA ECONOMIA E GESTÃO

ISSN 1984-6606

\section{$\mathrm{E}_{2} \mathrm{G}$}

\begin{tabular}{|c|c|c|c|c|c|c|c|c|c|c|}
\hline \multicolumn{2}{|c|}{ Grupos de Processo e Processos } & \multirow[t]{2}{*}{$\begin{array}{l}\text { Cooper et } \\
\text { al. (2001b) }\end{array}$} & \multirow[t]{2}{*}{$\begin{array}{l}\text { Miller } \\
\text { (2002) }\end{array}$} & \multirow{2}{*}{$\begin{array}{l}\text { Kendal e } \\
\text { Rollins } \\
(\mathbf{2 0 0 3})\end{array}$} & \multirow{2}{*}{$\begin{array}{l}\text { Callahan e } \\
\text { Brooks } \\
(2004)\end{array}$} & \multirow[t]{2}{*}{$\begin{array}{l}\text { Levine } \\
(2005)\end{array}$} & \multirow{2}{*}{$\begin{array}{l}\text { Martisuo e } \\
\text { Lehtonen } \\
\text { (2007) }\end{array}$} & \multirow{2}{*}{$\begin{array}{c}\text { PMI (2008) } \\
\mathrm{X}\end{array}$} & \multirow[t]{2}{*}{$\begin{array}{l}\text { IPMA } \\
(\mathbf{2 0 0 6 )}\end{array}$} & \multirow[t]{2}{*}{$\begin{array}{l}\text { OGC } \\
(2008)\end{array}$} \\
\hline & $\begin{array}{l}\text { Desenvolvimento do plano } \\
\text { de resposta a riscos }\end{array}$ & & & & & & & & & \\
\hline & $\begin{array}{l}\text { Balanceamento de } \\
\text { demanda, capacidade, } \\
\text { custos e de benefícios }\end{array}$ & $X$ & $\mathrm{X}$ & $\mathrm{X}$ & $\mathrm{X}$ & $X$ & & $X$ & $\mathrm{X}$ & $X$ \\
\hline & $\begin{array}{l}\text { Comunicação de ajustes em } \\
\text { portfólio }\end{array}$ & & & & & & & $X$ & & \\
\hline \multirow{5}{*}{ 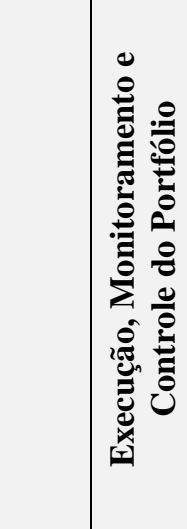 } & $\begin{array}{l}\text { Autorização de } \\
\text { componentes }\end{array}$ & & $X$ & & & & & $\mathrm{X}$ & & \\
\hline & $\begin{array}{l}\text { Monitoramento e controle } \\
\text { dos riscos do portfólio }\end{array}$ & & & & & & & $\mathrm{X}$ & $\mathrm{X}$ & \\
\hline & $\begin{array}{l}\text { Revisão e divulgação do } \\
\text { desempenho do portfólio }\end{array}$ & & $\mathrm{X}$ & $\mathrm{X}$ & & $X$ & & $X$ & & \\
\hline & $\begin{array}{l}\text { Envolvimento das partes } \\
\text { interessadas }\end{array}$ & & & & & & & & & $X$ \\
\hline & $\begin{array}{l}\text { Monitorar mudanças na } \\
\text { estratégia de negócio }\end{array}$ & & $\mathrm{X}$ & & & & & $\mathrm{X}$ & $X$ & \\
\hline \multirow{3}{*}{$\begin{array}{c}\text { Gestão de } \\
\text { Programa e } \\
\text { Projetos }\end{array}$} & $\begin{array}{l}\text { Gerenciamento dos } \\
\text { programas e projetos }\end{array}$ & & & & & & & $\mathrm{X}$ & $\mathrm{X}$ & $\mathrm{X}$ \\
\hline & $\begin{array}{l}\text { Medição de desempenho de } \\
\text { programas e projetos }\end{array}$ & & & & & & & $\mathrm{X}$ & $\mathrm{X}$ & \\
\hline & $\begin{array}{l}\text { Encerramento dos } \\
\text { programas e projetos }\end{array}$ & & & & & & & $\mathrm{X}$ & $\mathrm{X}$ & $\mathrm{X}$ \\
\hline
\end{tabular}




\begin{tabular}{|c|c|c|c|c|c|c|c|c|c|c|}
\hline \multicolumn{2}{|c|}{ Grupos de Processo e Processos } & \multirow{2}{*}{$\begin{array}{l}\text { Cooper et } \\
\text { al. }(2001 b)\end{array}$} & \multirow{2}{*}{$\begin{array}{l}\text { Miller } \\
\text { (2002) }\end{array}$} & \multirow{2}{*}{$\begin{array}{l}\text { Kendal e } \\
\text { Rollins } \\
(\mathbf{2 0 0 3 )}\end{array}$} & \multirow{2}{*}{$\begin{array}{c}\text { Callahan e } \\
\text { Brooks } \\
(2004)\end{array}$} & \multirow[t]{2}{*}{$\begin{array}{l}\text { Levine } \\
\text { (2005) }\end{array}$} & \multirow{2}{*}{$\begin{array}{c}\text { Martisuo e } \\
\text { Lehtonen } \\
(2007)\end{array}$} & PMI (2008) & \multirow[t]{2}{*}{$\begin{array}{l}\text { IPMA } \\
\text { (2006) }\end{array}$} & \multirow{2}{*}{$\begin{array}{c}\text { OGC } \\
(2008)\end{array}$} \\
\hline $\begin{array}{c}\text { Adm. de } \\
\text { Operações }\end{array}$ & Operação & & & & & & & $\mathrm{X}$ & & \\
\hline
\end{tabular}


ucranes

Hrebiniak (2005) identificou as principais barreiras à implementação e execução da estratégia. Relacionando-se essas barreiras à gestão do portfólio de projetos, podem-se identificar diversos processos que potencialmente as minimizam ou mesmo as eliminam (QUADRO 3).

\section{Quadro 3 - Principais barreiras à implementação do portfólio de projetos}

\begin{tabular}{|c|c|c|c|}
\hline \multicolumn{3}{|c|}{$\begin{array}{c}\text { Grupos de Processos de Gestão de portfólio, adaptado de } \\
\text { Sanchez, Robert e Pellerin, (2008) }\end{array}$} & \multirow[t]{2}{*}{ Barreiras identificadas em Hrebiniak (2005) } \\
\hline $\begin{array}{r}\text { Adm } \\
\text { Est }\end{array}$ & $\begin{array}{l}\text { ação } \\
\text { ica }\end{array}$ & $\begin{array}{c}\text { Missão e Visão, Planejamento } \\
\text { Estratégico, Objetivos Estratégicos e } \\
\text { Indicadores }\end{array}$ & \\
\hline \multirow{8}{*}{ 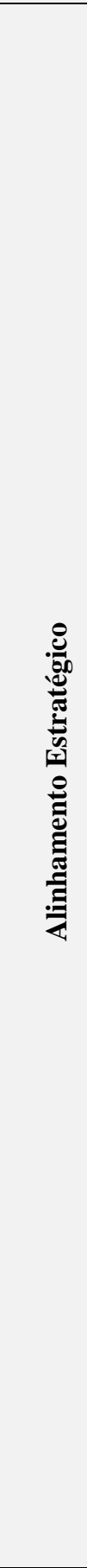 } & \multirow{3}{*}{ 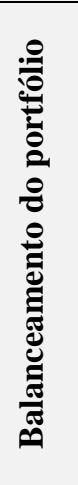 } & $\begin{array}{c}\text { Identificação dos riscos do portfólio, } \\
\text { Análise dos riscos do portfólio e } \\
\text { Desenvolvimento do plano de resposta } \\
\text { a riscos }\end{array}$ & $\begin{array}{l}\text { - Pouca habilidade em gerir a mudança de } \\
\text { maneira efetiva para ultrapassar a resistência } \\
\text { interna à mudança; } \\
\text { - Tentar executar uma estratégia conflitante com a } \\
\text { estrutura de poder vigente; }\end{array}$ \\
\hline & & $\begin{array}{l}\text { Balanceamento do portfólio: demanda } \\
\text { vs. capacidade, adm. financeira e de } \\
\text { benefícios }\end{array}$ & $\begin{array}{l}\text { - Falta de comunicação das responsabilidades } \\
\text { associadas à execução da estratégia em relação a } \\
\text { tomada de decisões ou ações associadas a } \\
\text { implementação. }\end{array}$ \\
\hline & & Comunicação de ajustes em portfólio & $\begin{array}{l}\text { - Falta de um entendimento comum do papel da } \\
\text { estrutura e desenho organizacional no processo de } \\
\text { implementação. }\end{array}$ \\
\hline & \multirow{5}{*}{ 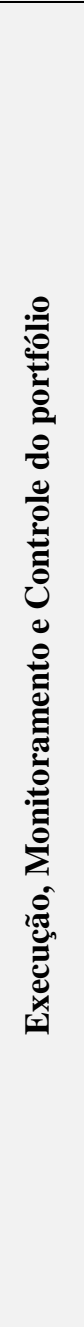 } & Autorização de componentes & $\begin{array}{l}\text { - Falta de um guia ou modelo que pudesse guiar } \\
\text { os esforços de implementação e execução } \\
\text { estratégia; } \\
\text { - Falta de um entendimento comum do papel da } \\
\text { estrutura e desenho organizacional no processo de } \\
\text { implementação. }\end{array}$ \\
\hline & & $\begin{array}{l}\text { Monitoramento e controle dos riscos do } \\
\text { portfólio }\end{array}$ & $\begin{array}{l}\text { - Pouca habilidade em gerir a mudança de } \\
\text { maneira efetiva para ultrapassar a resistência } \\
\text { interna à mudança; } \\
\text { - Tentar executar uma estratégia conflitante com a } \\
\text { estrutura de poder vigente; }\end{array}$ \\
\hline & & $\begin{array}{l}\text { Revisão e divulgação do desempenho } \\
\text { do portfólio }\end{array}$ & $\begin{array}{l}\text { - Compartilhamento pobre ou inadequado de } \\
\text { informações entre indivíduos ou unidades de } \\
\text { negócio responsáveis pela execução da estratégia. }\end{array}$ \\
\hline & & Envolvimento das partes interessadas & $\begin{array}{l}\text { - Pouca habilidade em gerir a mudança de } \\
\text { maneira efetiva para ultrapassar a resistência } \\
\text { interna à mudança; } \\
\text { - Tentar executar uma estratégia conflitante com a } \\
\text { estrutura de poder vigente; } \\
\text { - Falta de comunicação das responsabilidades } \\
\text { associadas à execução da estratégia em relação à } \\
\text { tomada de decisões ou ações associadas a } \\
\text { implementação; } \\
\text { - Falta de sentimento de propriedade } \\
\text { (comprometimento) de empregados-chave com a } \\
\text { estratégia ou planos de execução. }\end{array}$ \\
\hline & & $\begin{array}{l}\text { Monitorar mudanças na estratégia de } \\
\text { negócio }\end{array}$ & $\begin{array}{l}\text { - Compartilhamento pobre ou inadequado de } \\
\text { informações entre indivíduos ou unidades de } \\
\text { negócio responsáveis pela execução da estratégia; } \\
\text { - Falta de comunicação das responsabilidades } \\
\text { associadas à execução da estratégia em relação a } \\
\text { tomada de decisões ou ações associadas a } \\
\text { implementação. }\end{array}$ \\
\hline
\end{tabular}

Fonte: Elaborado pelos autores com base em HREBINIAK, 2005. 


\section{METODOLOGIA E COLETA DE DADOS}

Neste trabalho, apresenta-se um estudo quantitativo das percepções dos stakeholders de projetos de uma amostra de organizações no Brasil sobre as práticas que promovem o alinhamento dos projetos com a estratégia, bem como sobre as estruturas organizacionais que sustentam e promovem, de maneira efetiva, essa integração entre estratégia e projetos.

A percepção da importância das práticas e estruturas que promovem o alinhamento dos projetos com a estratégia nas organizações foi analisada segundo a percepção de uma amostra de praticantes do mundo dos projetos. Também se procurou avaliar a estruturação necessária para sustentar a administração de projetos, focalizando elementos como treinamento e desenvolvimento de pessoas, disponibilização de recursos, de sistemas e de tecnologia de gestão de projetos, alocação adequada de patrocinadores aos projetos, utilização de múltiplos critérios para avaliação do sucesso de um determinado projeto e, finalmente, a concessão de autoridade necessária aos gerentes de projetos.

A pesquisa foi realizada por meio de questionário eletrônico, aplicado a uma amostra de conveniência, buscando atingir o maior número de respondentes possíveis (GIL, 2006) que tivessem exposição direta ao tema. O questionário obteve 212 respostas válidas, representando 44 organizações distintas. O questionário passou por um pré-teste com dois profissionais e três pesquisadores para posteriormente ser distribuído, por meio de correio eletrônico, para membros de redes sociais ligadas ao tema via LinkedIn, redes sociais de exalunos de Administração da Universidade de São Paulo, alunos e ex-alunos de cursos de MBA da FIA (Fundação Instituto de Administração) e do Programa de Educação Continuada da Escola Politécnica da Universidade de São Paulo, além da rede pessoal de contatos dos pesquisadores que foram selecionados pelo critério de análise de currículo.

As questões buscam captar a percepção dos respondentes, por meio da análise de graus de concordância (escala Likert de 5 pontos), em relação a diversos itens de percepção de importância da gestão de projetos interligada à administração estratégica (QUADRO 4). 
Quadro 4 - Questões visando medir a dimensão de importância da gestão de projetos

Minha organização reconhece a importância...

...do alinhamento dos projetos à estratégia organizacional?

...da gestão de projetos para sobrevivência de longo prazo?

...da gestão de projetos para criação e sustentação de vantagem competitiva?

...do treinamento e desenvolvimento das pessoas em gestão de projetos para alcançar níveis mais elevados de sucesso nos projetos e na implementação das estratégias da empresa?

...da disponibilização de recursos adequados para bom andamento dos projetos?

...da disponibilização de sistemas e tecnologia de gestão de projetos para bom andamento dos projetos?

...da alocação adequada de patrocinadores aos projetos para alcançar níveis mais elevados de sucesso nos projetos e na implementação das estratégias da empresa?

...da utilização de múltiplos critérios para avaliação do sucesso dos projetos?

...da concessão de autoridade necessária aos gerentes de projetos para alcançar níveis mais elevados de sucesso nos projetos e na implementação das estratégias da empresa?

Fonte: Elaborado pelos autores.

Também foram selecionadas as dezenove perguntas do questionário de avaliação de maturidade em gestão de projetos do PMI (2006), para mensurar a percepção da maturidade em iniciação e planejamento de projetos com o objetivo de avaliar uma possível correlação entre maturidade de gestão de projeto e alinhamento estratégico do portfólio.

No processo de coleta de dados, 440 respondentes visualizaram o questionário, 347 respondentes responderam parcialmente ao questionário e 212 questionários foram considerados válidos e representam 44 empresas. Os questionários foram considerados válidos sob os seguintes critérios:

a) foram excluídos questionários que foram respondidos com todas as respostas nos centros ou nas pontas extremas (outliers) das escalas;

b) foram excluídos questionários que tiveram uma ou mais respostas nulas em qualquer pergunta da seção de percepção da importância da gestão de projetos;

c) foram excluídos questionários que tiveram uma ou mais respostas nulas em qualquer pergunta da seção percepção de maturidade na gestão de projetos.

\subsection{Análise dos dados}

As respostas computadas representaram o período de abril a junho de 2010 . Na Tabela 1 podem-se avaliar as características dos respondentes e, na Tabela 2, as características das empresas por eles representadas. 
Tabela 1 - Análise descritiva do perfil dos respondentes - abr./jun. 2010

Estagiário ou Trainee Grau hierárquico do respondente

Analista ou Operador

Líder ou Coordenador de Equipe

Gerente ou Superintendente de Área

Alta Administração, Diretor, VP ou C-Level

Total

\begin{tabular}{c|c|c} 
Frequência & Percentual & Perc. cumulativo \\
\hline 7 & 3,3 & 3,3 \\
30 & 14,2 & 17,5 \\
72 & 34,0 & 51,4 \\
70 & 33,0 & 84,4 \\
33 & 15,6 & 100,0 \\
$\mathbf{2 1 2}$ & $\mathbf{1 0 0 , 0}$ & \\
\hline
\end{tabular}

Fonte: Elaborado pelos autores.

Outras características relevantes dos respondentes são as seguintes: 82,90\% têm curso universitário, MBA, pós-graduação ou especialização; 85,30\% têm mais de sete anos de experiência profissional; $51,40 \%$ têm mais de sete anos de experiência profissional em projetos e 19,10\% tem alguma certificação em gestão de projetos.

Tabela 2 - Análise descritiva das organizações dos respondentes - abr./jun. 2010

\begin{tabular}{c|c|c}
\hline Faturamento & Número. de funcionários & Frequência \\
\hline $\begin{array}{c}\text { Pequenas e médias Empresas } \\
\text { (menor que R\$ 300 milhões/ano) }\end{array}$ & $>$ > 500 funcionários & 17 \\
Grandes empresas & $<499$ funcionários & 7 \\
(maior que R\$ 300 milhões/ano) & $>500$ funcionários & 95 \\
Não informado & Não informado & 2 \\
\hline
\end{tabular}

Fonte: Elaborado pelos autores.

Outras características relevantes das organizações representadas neste estudo são: 85,20\% atuam há mais de sete anos no mercado; 60,30\% são multinacionais e 69,20\% têm origem latino-americana, mais significativamente, brasileira.

As percepções de importância declaradas pelos respondentes podem ser observadas na Figura 2, na qual se pode destacar que as maiores importâncias atribuídas para a gestão de projetos, associada à estratégia organizacional, refletem a necessidade de sobrevivência da organização e da sustentação da vantagem competitiva.

Figura 2 - Análise descritiva das percepções de importância

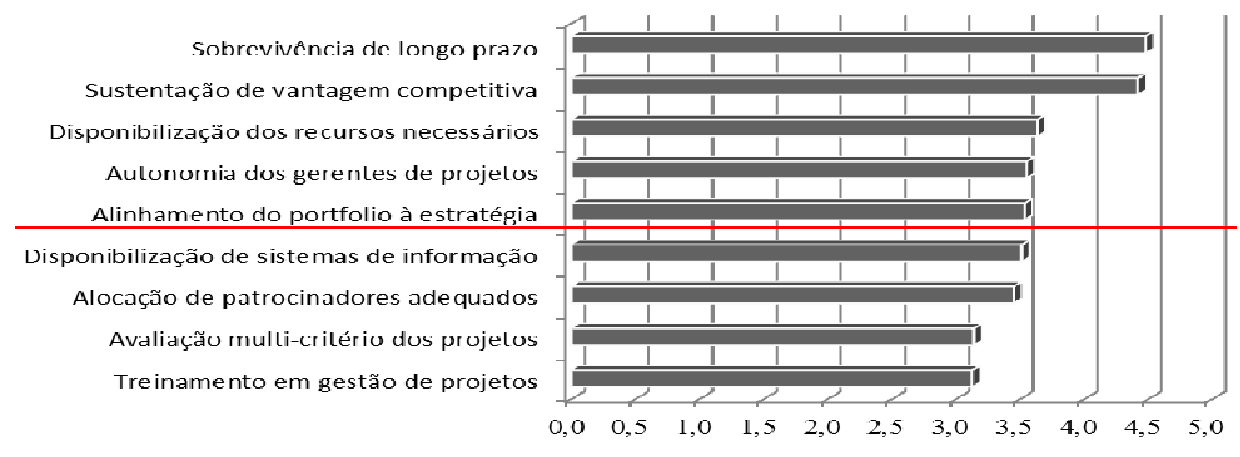

Fonte: Elaborado pelos autores. 
(oo

PUC Minas E\&G - REVISTA ECONOMIA E GESTÃo

ISSN 1984-6606

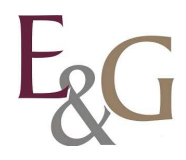

Foi realizada uma verificação estatística de distribuição das percepções de importância do alinhamento da gestão de projetos à estratégia organizacional, demonstrando uma distribuição não normal com cauda longa à esquerda, motivo pelo qual foi utilizado o teste não paramétrico de Kruskal-Wallis para as correlações entre variáveis (TAB. 3).

Tabela 3 - Teste de Normalidade Kolmogorov-Smirnov das percepções de importância abr./jun. 2010

\begin{tabular}{l|lr}
\hline \multicolumn{2}{c|}{ One-Sample Kolmogorov-Smirnov Test } & Importância \\
\hline $\mathrm{N}$ & Mean & 212 \\
\hline Normal Parameters ${ }^{\mathrm{a}, \mathrm{b}}$ & Std. Deviation & 32,8632 \\
& Absolute & 7,78230 \\
Most Extreme Differences & Positive &, 100 \\
& Negative &, 059 \\
& &,- 100 \\
\hline Kolmogorov-Smirnov Z & 1,455 \\
Asymp. Sig. (2-tailed) &, 029 \\
\hline \multicolumn{2}{c}{ a. Test distribution is Normal. Fonte: Elaborado pelos autores. }
\end{tabular}

As análises de diferenças de percepção de importância da gestão de projetos para o alinhamento de estratégia apontaram justificativa estatística consistente (Sig.0,015) permitindo inferir que empresas de grande porte (faturamento anual superior a $\mathrm{R} \$ 300$ milhões) possuem uma percepção total de importância maior que empresas pequenas e de médio porte (TAB. 4). Destacam-se as considerações de importância específicas relacionadas ao treinamento (Sig.0,013), alinhamento do projeto à estratégia (Sig.0,013), disponibilização de sistemas de gestão de projetos (Sig.0,033), alocação de patrocinadores (Sig.0,000) e utilização de critérios múltiplos de avaliação (Sig. 0,015). 
PUC Minas E\&G - REVISTA ECONOMIA E GESTÃO

ISSN 1984-6606

Tabela 4 - Teste de Kruskal Wallis entre a importância percebida e o faturamento abr./jun. 2010

\begin{tabular}{|c|c|c|c|c|c|c|}
\hline \multicolumn{4}{|l|}{ Ranks } & \multicolumn{3}{|c|}{ Statistics tests $^{\mathrm{a}, \mathrm{b}}$} \\
\hline & Faturamento & $\mathbf{N}$ & $\begin{array}{l}\text { Mean } \\
\text { Rank }\end{array}$ & \begin{tabular}{|l|} 
Chi- \\
square
\end{tabular} & Df & $\begin{array}{l}\text { Asymp. } \\
\text { Sig. }\end{array}$ \\
\hline Importância & $\begin{array}{l}\text { PME <R \$ } 300 \text { milhões } \\
\text { Grande :R\$ } 300 \text { milhões } \\
\text { Total }\end{array}$ & $\begin{array}{l}108 \\
102 \\
210\end{array}$ & $\begin{array}{c}95,63 \\
115,96\end{array}$ & 5,885 & 1 & ,015 \\
\hline $\begin{array}{l}\text { Sobrevivência de longo } \\
\text { prazo }\end{array}$ & $\begin{array}{l}\text { PME <R \$ } 300 \text { milhões } \\
\text { Grande }: \text { R } \$ 300 \text { milhões } \\
\text { Total }\end{array}$ & $\begin{array}{l}108 \\
102 \\
210\end{array}$ & $\begin{array}{l}104,73 \\
106,32\end{array}$ & ,049 & 1 &, 825 \\
\hline $\begin{array}{l}\text { Sustentação de } \\
\text { vantagem competitiva }\end{array}$ & $\begin{array}{l}\text { PME }<\mathrm{R} \$ 300 \text { milhões } \\
\text { Grande }: \mathrm{R} \$ 300 \text { milhões } \\
\text { Total }\end{array}$ & $\begin{array}{l}108 \\
102 \\
210\end{array}$ & $\begin{array}{l}105,81 \\
105,17\end{array}$ & ,008 & 1 & ,930 \\
\hline $\begin{array}{l}\text { Treinamento em gestão } \\
\text { de projetos }\end{array}$ & $\begin{array}{l}\text { PME <R \$ } 300 \text { milhões } \\
\text { Grande :R\$ } 300 \text { milhões } \\
\text { Total }\end{array}$ & $\begin{array}{l}108 \\
102 \\
210\end{array}$ & $\begin{array}{c}95,72 \\
115,85\end{array}$ & 6,190 & 1 & ,013 \\
\hline $\begin{array}{l}\text { Alinhamento dos } \\
\text { projetos à estratégia } \\
\text { organizacional }\end{array}$ & $\begin{array}{l}\text { PME <R \$ } 300 \text { milhões } \\
\text { Grande }: \mathrm{R} \$ 300 \text { milhões } \\
\text { Total }\end{array}$ & $\begin{array}{l}108 \\
102 \\
210\end{array}$ & $\begin{array}{c}95,81 \\
115,75\end{array}$ & 6,119 & 1 & ,013 \\
\hline $\begin{array}{l}\text { Disponibilização de } \\
\text { recursos }\end{array}$ & $\begin{array}{l}\text { PME <R \$ } 300 \text { milhões } \\
\text { Grande :R\$ } 300 \text { milhões } \\
\text { Total }\end{array}$ & $\begin{array}{l}108 \\
102 \\
210\end{array}$ & $\begin{array}{l}101,34 \\
109,90\end{array}$ & 1,160 & 1 & ,281 \\
\hline $\begin{array}{l}\text { Disponibilização de } \\
\text { sistemas de gestão de } \\
\text { projetos }\end{array}$ & $\begin{array}{l}\text { PME }<\mathrm{R} \$ 300 \text { milhões } \\
\text { Grande }: \mathrm{R} \$ 300 \text { milhões } \\
\text { Total }\end{array}$ & $\begin{array}{l}108 \\
102 \\
210\end{array}$ & $\begin{array}{c}97,24 \\
114,25\end{array}$ & 4,522 & 1 & ,033 \\
\hline $\begin{array}{l}\text { Alocação de } \\
\text { patrocinadores }\end{array}$ & $\begin{array}{l}\text { PME <R \$ } 300 \text { milhões } \\
\text { Grande :R\$ } 300 \text { milhões } \\
\text { Total }\end{array}$ & $\begin{array}{l}108 \\
102 \\
210\end{array}$ & $\begin{array}{c}89,77 \\
122,15\end{array}$ & 15,988 & 1 & ,000 \\
\hline $\begin{array}{l}\text { Utilização de critérios } \\
\text { de avaliação }\end{array}$ & $\begin{array}{l}\text { PME <R \$ } 300 \text { milhões } \\
\text { Grande }: \mathrm{R} \$ 300 \text { milhões } \\
\text { Total }\end{array}$ & $\begin{array}{l}108 \\
102 \\
210\end{array}$ & $\begin{array}{c}95,89 \\
115,68\end{array}$ & 5,933 & 1 &, 015 \\
\hline $\begin{array}{l}\text { Concessão de autonomia } \\
\text { aos Gerentes de Projetos }\end{array}$ & $\begin{array}{l}\text { PME <R \$ } 300 \text { milhões } \\
\text { Grande }: R \$ 300 \text { milhões } \\
\text { Total }\end{array}$ & $\begin{array}{l}108 \\
102 \\
210\end{array}$ & $\begin{array}{l}104,30 \\
106,77\end{array}$ & ,095 & 1 &, 757 \\
\hline
\end{tabular}

De forma diversa, fazendo-se a correlação entre o número de funcionários e as percepções de importância para diferentes grupos de empresas (grandes com mais de 500 funcionários e pequenas/médias com menos de 500 funcionários), não foram encontradas justificativas estatísticas suficientes capazes de apontar que diferentes percepções de importância do alinhamento de gestão de projetos com a estratégia pudessem ser caracterizadas por esses agrupamentos (Sig. 0,2510), com exceção do item específico de alocação de patrocinadores para os projetos (Sig. 0,010), em que empresas com maior número de funcionários apontaram maior importância para esse item, que empresas com menor número de funcionários.

Quando analisadas as percepções de importância para os diversos setores de atuação (serviços, comercial, manufatureiro, setor público e terceiro setor), também não foram encontradas justificativas estatísticas suficientes que permitissem agrupamentos distintos da 
PUC Minas

percepção total de importância (TAB. 5), tanto de forma individualizada (Sig. 0,064), como de forma agrupada (Sig.0,769).

Tabela 5 - Teste de Kruskal Wallis entre a importância percebida e o setor de atuação abr./jun. 2010

\begin{tabular}{|c|c|c|c|c|c|c|}
\hline \multicolumn{4}{|l|}{ Ranks } & \multicolumn{3}{|c|}{ Statistics tests $^{\text {a,b }}$} \\
\hline & Setor & $\mathbf{N}$ & $\begin{array}{l}\text { Mean } \\
\text { Rank }\end{array}$ & $\begin{array}{c}\text { Chi- } \\
\text { square }\end{array}$ & df & $\begin{array}{c}\text { Asymp. } \\
\text { Sig. }\end{array}$ \\
\hline Importância & \begin{tabular}{|l|} 
Serviços \\
Comercial \\
Manufatureiro \\
Setor Público \\
Terceiro Setor \\
Total \\
\end{tabular} & $\begin{array}{c}144 \\
3 \\
53 \\
8 \\
1 \\
209 \\
\end{array}$ & $\begin{array}{c}107,03 \\
151,50 \\
102,90 \\
55,63 \\
180,00\end{array}$ & 8,889 & 4 & ,064 \\
\hline \multicolumn{4}{|l|}{ Ranks } & \multicolumn{3}{|c|}{ Statistics tests $^{\text {a,c }}$} \\
\hline & Setor Agrupado & $\mathbf{N}$ & $\begin{array}{l}\text { Mean } \\
\text { Rank }\end{array}$ & $\begin{array}{l}\text { Chi- } \\
\text { square }\end{array}$ & df & $\begin{array}{l}\text { Asymp. } \\
\text { Sig. }\end{array}$ \\
\hline Importância & \begin{tabular}{|l} 
Serviços, Comercial, \\
Setor Público e $3^{\circ}$ Setor \\
Manufatureira \\
Total \\
\end{tabular} & $\begin{array}{l}156 \\
53 \\
209 \\
\end{array}$ & $\begin{array}{l}105,71 \\
102,90\end{array}$ &, 086 & 1 &, 769 \\
\hline
\end{tabular}

Da mesma forma, quando analisadas as percepções de importância de acordo com a origem da empresa do respondente (latino-americana, norte-americana, europeia ou asiática), também não foram encontradas justificativas estatísticas suficientes que permitissem agrupamentos distintos da percepção total de importância (TAB. 6), tanto de forma individualizada (Sig. 0,058), como de forma agrupada (Sig.0,479).

Tabela 6 - Teste de Kruskal Wallis entre a importância percebida e a origem da empresa - abr./jun. 2010

\begin{tabular}{|c|c|c|c|c|c|c|}
\hline \multicolumn{4}{|l|}{ Ranks } & \multicolumn{3}{|c|}{ Statistics tests $^{\text {a,b }}$} \\
\hline & Origem & $\mathbf{N}$ & $\begin{array}{l}\text { Mean } \\
\text { Rank }\end{array}$ & $\begin{array}{c}\text { Chi- } \\
\text { square }\end{array}$ & df & $\begin{array}{l}\text { Asymp. } \\
\text { Sig. }\end{array}$ \\
\hline Importância & $\begin{array}{l}\text { Latino americana } \\
\text { Norte americana } \\
\text { Européia } \\
\text { Asiática } \\
\text { Total } \\
\end{array}$ & $\begin{array}{c}144 \\
22 \\
39 \\
3 \\
208 \\
\end{array}$ & $\begin{array}{c}102,53 \\
127,32 \\
94,24 \\
164,83\end{array}$ & 7,479 & 3 &, 058 \\
\hline \multicolumn{4}{|l|}{ Ranks } & \multicolumn{3}{|c|}{ Statistics tests $^{\text {a,c }}$} \\
\hline & Origem Agrupada & $\mathbf{N}$ & $\begin{array}{l}\text { Mean } \\
\text { Rank } \\
\end{array}$ & $\begin{array}{c}\text { Chi- } \\
\text { square }\end{array}$ & df & $\begin{array}{c}\text { Asymp. } \\
\text { Sig. }\end{array}$ \\
\hline Importância & $\begin{array}{l}\text { Latino americanas } \\
\text { Norte americanas, } \\
\text { Europeias e Asiáticas } \\
\text { Total }\end{array}$ & $\begin{array}{l}144 \\
64 \\
208\end{array}$ & $\begin{array}{l}102,53 \\
108,92\end{array}$ & ,500 & 1 & ,479 \\
\hline
\end{tabular}


A análise de correlação entre o nível hierárquico do respondente e o grau de importância do alinhamento da gestão de projetos com a estratégia organizacional apontou a possibilidade de agrupamentos distintos de percepção, em que respondentes alocados em posições estratégicas (presidência, diretoria e gerência) possuíam uma consideração de importância geral maior que respondentes em níveis hierárquicos em posições operacionais (coordenadores, analistas, trainees e estagiários) (Sig. 0,021), ocorrendo da mesma forma, para percepções específicas de importância para sobrevivência a longo prazo (Sig.0,009), sustentação de vantagem competitiva (Sig.0,045), disponibilização de sistema de gestão de projetos (Sig.0,038) e concessão de autonomia aos gestores de projetos (Sig.0,040), como pode ser observado na Tabela 7.

Tabela 7 - Teste de Kruskal Wallis entre a importância percebida e o nível hierárquico do respondente - abr./jun. 2010

\begin{tabular}{|c|c|c|c|c|c|c|}
\hline \multicolumn{4}{|l|}{ Ranks } & \multicolumn{3}{|c|}{ Statistics tests $^{\mathbf{a}, \mathrm{b}}$} \\
\hline Nível hierárquico & & $\mathbf{N}$ & $\begin{array}{l}\text { Mean } \\
\text { Rank }\end{array}$ & $\begin{array}{c}\text { Chi- } \\
\text { square }\end{array}$ & df & $\begin{array}{l}\text { Asymp. } \\
\text { Sig. }\end{array}$ \\
\hline Importância & $\begin{array}{l}\text { Operacional } \\
\text { Estratégico } \\
\text { Total }\end{array}$ & $\begin{array}{l}109 \\
103 \\
212\end{array}$ & $\begin{array}{c}97,08 \\
116,47\end{array}$ & 5,299 & 1 & ,021 \\
\hline $\begin{array}{l}\text { Sobrevivência de longo } \\
\text { prazo }\end{array}$ & $\begin{array}{l}\text { Operacional } \\
\text { Estratégico } \\
\text { Total }\end{array}$ & $\begin{array}{l}109 \\
103 \\
212\end{array}$ & $\begin{array}{c}97,26 \\
116,28\end{array}$ & 6,868 & 1 & ,009 \\
\hline $\begin{array}{l}\text { Sustentação de vantagem } \\
\text { competitiva }\end{array}$ & $\begin{array}{l}\text { Operacional } \\
\text { Estratégico } \\
\text { Total }\end{array}$ & $\begin{array}{l}109 \\
103 \\
212\end{array}$ & $\begin{array}{c}99,28 \\
114,15\end{array}$ & 4,034 & 1 &, 045 \\
\hline $\begin{array}{l}\text { Treinamento em gestão de } \\
\text { projetos }\end{array}$ & $\begin{array}{l}\text { Operacional } \\
\text { Estratégico } \\
\text { Total }\end{array}$ & $\begin{array}{l}109 \\
103 \\
212\end{array}$ & $\begin{array}{l}101,45 \\
111,84\end{array}$ & 1,633 & 1 & ,201 \\
\hline $\begin{array}{l}\text { Alinhamento dos projetos à } \\
\text { estratégia organizacional }\end{array}$ & $\begin{array}{l}\text { Operacional } \\
\text { Estratégico } \\
\text { Total }\end{array}$ & $\begin{array}{l}109 \\
103 \\
212\end{array}$ & $\begin{array}{l}100,22 \\
113,15\end{array}$ & 2,552 & 1 & , 110 \\
\hline $\begin{array}{l}\text { Disponibilização de } \\
\text { recursos }\end{array}$ & $\begin{array}{l}\text { Operacional } \\
\text { Estratégico } \\
\text { Total }\end{array}$ & $\begin{array}{l}109 \\
103 \\
212\end{array}$ & $\begin{array}{l}101,00 \\
112,32\end{array}$ & 2,011 & 1 & , 156 \\
\hline $\begin{array}{l}\text { Disponibilização de } \\
\text { sistemas de gestão de } \\
\text { projetos }\end{array}$ & $\begin{array}{l}\text { Operacional } \\
\text { Estratégico } \\
\text { Total }\end{array}$ & $\begin{array}{l}109 \\
103 \\
212\end{array}$ & $\begin{array}{c}98,41 \\
115,06\end{array}$ & 4,288 & 1 & ,038 \\
\hline Alocação de patrocinadores & $\begin{array}{l}\text { Operacional } \\
\text { Estratégico } \\
\text { Total }\end{array}$ & $\begin{array}{l}109 \\
103 \\
212\end{array}$ & $\begin{array}{l}103,37 \\
109,82\end{array}$ & 629 & 1 & ,428 \\
\hline $\begin{array}{l}\text { Utilização de critérios de } \\
\text { avaliação }\end{array}$ & $\begin{array}{l}\text { Operacional } \\
\text { Estratégico } \\
\text { Total }\end{array}$ & $\begin{array}{l}109 \\
103 \\
212\end{array}$ & $\begin{array}{l}100,27 \\
113,10\end{array}$ & 2,469 & 1 & ,116 \\
\hline $\begin{array}{l}\text { Concessão de autonomia } \\
\text { aos Gerentes de Projetos }\end{array}$ & $\begin{array}{l}\text { Operacional } \\
\text { Estratégico } \\
\text { Total }\end{array}$ & $\begin{array}{l}109 \\
103 \\
212\end{array}$ & $\begin{array}{c}98,47 \\
115,00\end{array}$ & 4,221 & 1 & ,040 \\
\hline
\end{tabular}

a. Kruskal Wallis Test 
Respondentes mais experientes consideram maior importância geral à gestão de projetos, como auxiliar para o alinhamento estratégico (Sig.0,003), da mesma forma para a sobrevivência a longo prazo (Sig.0,009), sustentação de vantagem competitiva (Sig.0,045), disponibilização de sistemas de gestão de projetos (Sig.0,038) e concessão de autonomia para os gerentes de projeto (Sig. 0,040). Outra correlação importante a ser considerada apontou para identificação de percepções distintas de importância em função do tempo de experiência dos respondentes (TAB. 8).

Tabela 8 - Teste de Kruskal Wallis entre a importância percebida e a experiência do respondente - abr./jun. 2010

\begin{tabular}{|c|c|c|c|c|c|c|}
\hline \multicolumn{4}{|l|}{ Ranks } & \multicolumn{3}{|c|}{ Statistics tests $^{\mathrm{a}, \mathrm{b}}$} \\
\hline & Experiência total & $\mathbf{N}$ & $\begin{array}{l}\text { Mean } \\
\text { Rank }\end{array}$ & $\begin{array}{c}\text { Chi- } \\
\text { square }\end{array}$ & df & $\begin{array}{c}\text { Asymp. } \\
\text { Sig. }\end{array}$ \\
\hline Importância & $\begin{array}{l}\text { Menor que } 10 \text { anos } \\
\text { Maior que } 10 \text { anos } \\
\text { Total }\end{array}$ & $\begin{array}{c}62 \\
149 \\
211\end{array}$ & $\begin{array}{c}86,37 \\
114,17\end{array}$ & 9,095 & 1 & ,003 \\
\hline $\begin{array}{l}\text { Sobrevivência de longo } \\
\text { prazo }\end{array}$ & $\begin{array}{l}\text { Menor que } 10 \text { anos } \\
\text { Maior que } 10 \text { anos } \\
\text { Total }\end{array}$ & $\begin{array}{c}62 \\
149 \\
211\end{array}$ & $\begin{array}{c}93,04 \\
111,39\end{array}$ & 5,350 & 1 & ,021 \\
\hline $\begin{array}{l}\text { Sustentação de vantagem } \\
\text { competitiva }\end{array}$ & $\begin{array}{l}\text { Menor que } 10 \text { anos } \\
\text { Maior que } 10 \text { anos } \\
\text { Total }\end{array}$ & $\begin{array}{c}62 \\
149 \\
211\end{array}$ & $\begin{array}{c}96,40 \\
110,00\end{array}$ & 2,811 & 1 & ,003 \\
\hline $\begin{array}{l}\text { Treinamento em gestão } \\
\text { de projetos }\end{array}$ & $\begin{array}{l}\text { Menor que } 10 \text { anos } \\
\text { Maior que } 10 \text { anos } \\
\text { Total }\end{array}$ & $\begin{array}{c}62 \\
149 \\
211\end{array}$ & $\begin{array}{c}95,56 \\
110,35\end{array}$ & 2,765 & 1 & ,096 \\
\hline $\begin{array}{l}\text { Alinhamento dos } \\
\text { projetos à estratégia } \\
\text { organizacional }\end{array}$ & $\begin{array}{l}\text { Menor que } 10 \text { anos } \\
\text { Maior que } 10 \text { anos } \\
\text { Total }\end{array}$ & $\begin{array}{c}62 \\
149 \\
211\end{array}$ & $\begin{array}{c}94,72 \\
110,69\end{array}$ & 3,246 & 1 & ,072 \\
\hline $\begin{array}{l}\text { Disponibilização de } \\
\text { recursos }\end{array}$ & $\begin{array}{l}\text { Menor que } 10 \text { anos } \\
\text { Maior que } 10 \text { anos } \\
\text { Total }\end{array}$ & $\begin{array}{c}62 \\
149 \\
211\end{array}$ & $\begin{array}{c}91,45 \\
112,05\end{array}$ & 5,551 & 1 & ,018 \\
\hline $\begin{array}{l}\text { Disponibilização de } \\
\text { sistemas de gestão de } \\
\text { projetos }\end{array}$ & $\begin{array}{l}\text { Menor que } 10 \text { anos } \\
\text { Maior que } 10 \text { anos } \\
\text { Total }\end{array}$ & $\begin{array}{c}62 \\
149 \\
211\end{array}$ & $\begin{array}{c}87,28 \\
113,79\end{array}$ & 9,051 & 1 & ,003 \\
\hline $\begin{array}{l}\text { Alocação de } \\
\text { patrocinadores }\end{array}$ & $\begin{array}{l}\text { Menor que } 10 \text { anos } \\
\text { Maior que } 10 \text { anos } \\
\text { Total }\end{array}$ & $\begin{array}{c}62 \\
149 \\
211\end{array}$ & $\begin{array}{c}87,00 \\
113,91\end{array}$ & 9,152 & 1 & ,002 \\
\hline $\begin{array}{l}\text { Utilização de critérios de } \\
\text { avaliação }\end{array}$ & $\begin{array}{l}\text { Menor que } 10 \text { anos } \\
\text { Maior que } 10 \text { anos } \\
\text { Total }\end{array}$ & $\begin{array}{c}62 \\
149 \\
211\end{array}$ & $\begin{array}{c}90,64 \\
112,39\end{array}$ & 5,926 & 1 & ,015 \\
\hline $\begin{array}{l}\text { Concessão de autonomia } \\
\text { aos Gerentes de Projetos }\end{array}$ & $\begin{array}{l}\text { Menor que } 10 \text { anos } \\
\text { Maior que } 10 \text { anos } \\
\text { Total }\end{array}$ & $\begin{array}{c}62 \\
149 \\
211\end{array}$ & $\begin{array}{c}93,83 \\
111,06\end{array}$ & 3,828 & 1 & 050 \\
\hline
\end{tabular}

a. Kruskal Wallis Test b. Grouping Variable: Experiência_total_agrupado Fonte: Elaborado pelos autores.

Considerando-se a percepção apontada pelos respondentes do nível de maturidade em iniciação e planejamento de projetos, medido com base na escala de maturidade do OPM3 (PMI; 2006), com a inclusão de um nível inicial de maturidade que se encontra nos modelos Maximiano e Rabechini (2002) e Kerzner (2000), podem-se considerar dois grupos distintos: 
empresas com baixo grau de maturidade (níveis inferiores à mediana) e empresas com alto grau de maturidade (níveis superiores à mediana). As análises estatísticas apontam para uma correlação positiva entre os níveis de importância da gestão de projetos como elemento alinhado à estratégia organizacional, com o nível de maturidade dessas empresas, tanto em nível geral (Sig. 0,000), como na avaliação de cada importância específica, conforme pode ser observado na Tabela 9.

Tabela 9 - Teste de Kruskal Wallis entre a importância percebida e o nível de maturidade em gestão de projetos - abr./jun. 2010

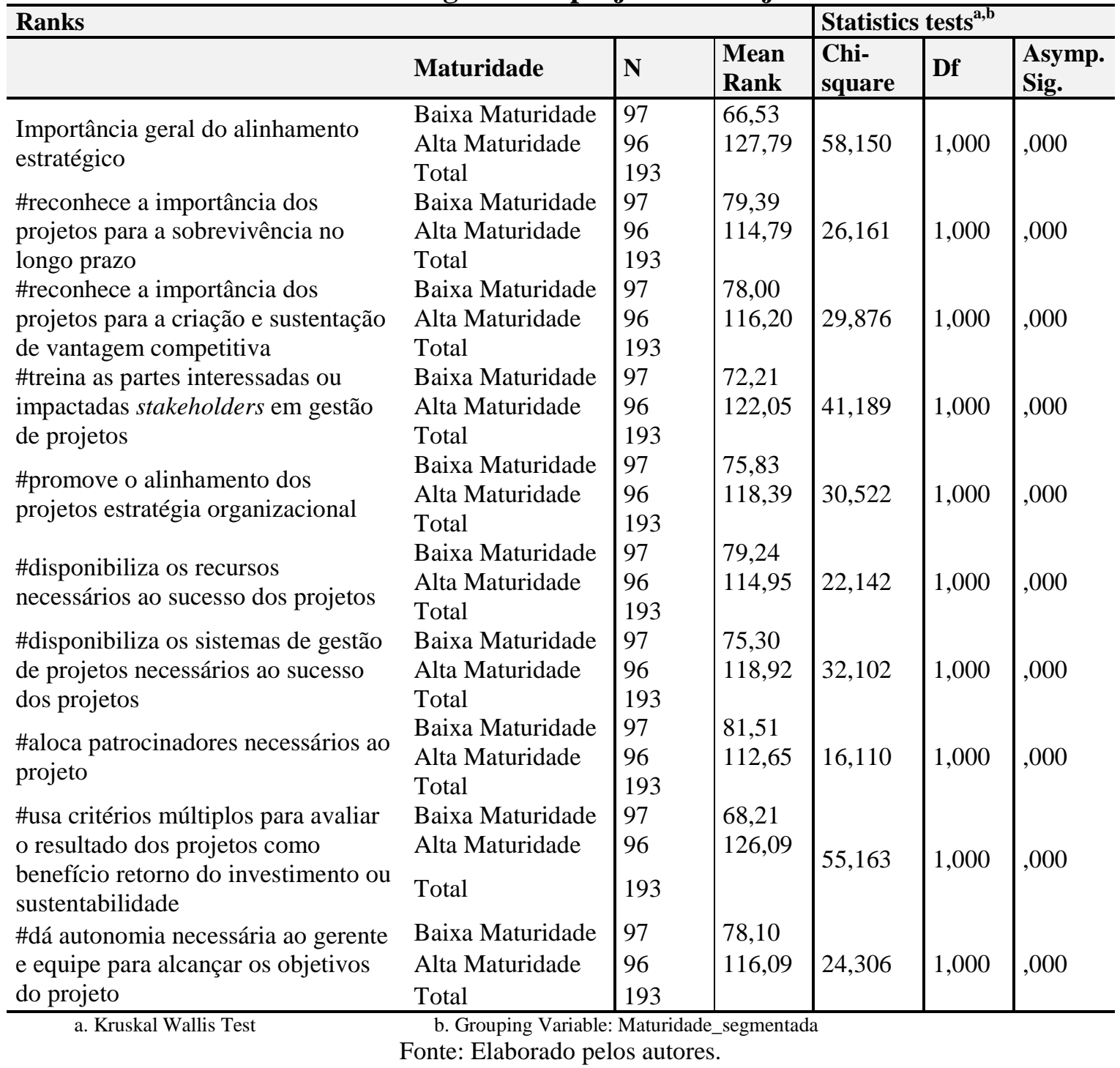

Por fim, foi verificado que o fato de o respondente possuir ou não certificações em gestão de projetos (PMI, CAPM, PMP, OGG, PRINCE2), gestão de qualidade (SixSigma) ou outras relacionadas à gestão não caracteriza um agrupamento justificável estatisticamente em 
PUC Minas E\&G - REVISTA ECONOMIA E GESTÃO relação à percepção total de importância (Sig. 0,938), ou dos itens analisados individualmente. 


\section{CONSIDERAÇÕES FINAIS}

De forma geral, a missão e os objetivos estratégicos PMI (2008) da organização direcionam o processo de gerenciamento do planejado em realidade para determinar a posição estratégica futura. Embora grande parte dos estudos acadêmicos considerem a formulação da estratégia o fator-chave de sucesso no direcionamento futuro, a implementação é caracterizada pelos gestores como a fase crítica para o sucesso da gestão estratégica. (HREBINIAK, 2005).

Ao longo do tempo essa abordagem despertou o interesse de alguns acadêmicos Shenhar, (1999), Kathuria, Joshi e Porth (2007), Artto e Dietrich (2004), Jamieson e Morris (2004), Srivannaboon e Milosevic (2004), Dietrich e Lehtonen (2005) e Srivannaboon (2006), que buscavam explicar como a gestão competente do portfólio de projetos poderia ser considerada fator crítico para construção e manutenção de vantagens competitivas para as organizações.

Pode-se inferir que as características necessárias para suportar e fomentar uma gestão integrada da execução da estratégia deliberada e emergente podem estar mais presentes em grandes organizações ou com maior maturidade em gestão de projetos. Os resultados suportam a hipótese de que as empresas de grande porte (faturamento anual superior a $\mathrm{R} \$ 300$ milhões) possuem uma percepção total de importância maior que empresas pequenas e de médio porte quanto aos seguintes elementos: treinamento, alinhamento do projeto à estratégia, disponibilização de sistemas de gestão de projetos, alocação de patrocinadores e utilização de critérios múltiplos de avaliação.

O alinhamento estratégico dos projetos é facilitado pela existência de alguns fatores viabilizadores estruturais, os organizational enablers (PMI, 2008). Sendo assim, a gestão de portfólio e o alinhamento estratégico são facilitadores da difusão da estratégia nos diversos níveis organizacionais, conforme discutido por Mintzberg (1994), Miller (2002), IPMA (2006) e PMI (2008). Essa pesquisa aponta evidências de maiores níveis de importância da gestão de projetos nas organizações com maior nível de maturidade em gestão de projetos OPM3® do PMI (2006), tanto em nível geral, como na avaliação de cada item específico.

Os resultados indicam que os fatores viabilizadores estruturais parecem ser mais valorizados por membros da alta administração e profissionais mais experientes e que os respondentes em posições estratégicas (presidência, diretoria e gerência) dão maior 
importância que respondentes em níveis hierárquicos em posições operacionais (coordenadores, analistas, trainees e estagiários) enquanto sobrevivência no longo prazo, sustentação de vantagem competitiva, disponibilização de sistema de gestão de projetos e concessão de autonomia aos gestores de projetos. Os respondentes mais experientes dão maior importância à gestão de projetos como fator que pode auxiliar o alinhamento estratégico para a sobrevivência no longo prazo, sustentação de vantagem competitiva, disponibilização de sistemas de gestão de projetos e concessão de autonomia para os gerentes de projeto.

Esse resultado confirma as ponderações de Mintzberg (1994) no sentido de que essas configurações buscam melhorar a integração entre as áreas e as unidades de negócio para que o conhecimento coletivo direcione os processos de ruptura da organização em prol de seus objetivos. Por essas razões, o perfil do gestor destaca-se como uma importante variável motivacional: ele indica as prioridades em relação à gestão e incentivos ao desenvolvimento de competências internas e externas para atingir metas estratégicas e de desempenho.

A análise de dados sugere evidências de uma possível correlação positiva entre os níveis de importância dada ao alinhamento dos projetos à estratégia, com o nível de maturidade em gestão de projetos dessas organizações. Assim, poder-se-ia inferir que as características necessárias para suportar e fomentar o alinhamento estratégico dos projetos podem estar mais presentes em grandes organizações com maior maturidade em gestão de projetos. Embora nos últimos anos muitas empresas estejam adotando a gestão de portfólio que ajuda a promover o alinhamento estratégico, o estudo indica que esse processo formalizado e estruturado é mais presente nas grandes empresas em consequência das dificuldades de monitoramento e alinhamento do portfólio de projetos. Essas características, contudo, ainda são pouco marcantes em empresas de pequeno e médio porte.

Questiona-se assim, com base em Blichfeldt e Eskerod (2008), uma possível lacuna nos modelos normativos de alinhamento estratégico do portfólio de projeto ao lidar com os projetos extraoficiais inferindo as teorias (MINTZBERG, 1984; COLLINS, 2001) que entendem a estratégia como um processo menos deliberado e muitas vezes emergente da execução e implementação. 


\section{REFERÊNCIAS}

ANDERSEN, E. S. Rethinking Project Management. Harlow: Pearson Education Limited, 2008

ANSELMO, J. L., MAXIMIANO, A. C. A. Gerenciamento Estratégico em Negócios Baseados em Projetos. SIMPOI 2010, 13, Simpósio de Administração da Produção, Logística e Operações Internacionais, 2010.

ARCHIBALD, R. D. A. Global System for Categorizing Projects: The Need for, Recommended Approach to, and Practical Uses of the System. 2nd Latin American Forum: PM in Government, Brasília, Brazil, 21-22 Sep. 2004.

ARTTO, K.; DIETRICH, P. Strategic business management through multiple projects. In: MORRIS, P.W.G.; PINTO, J.K., editors. The Wiley Guide to Managing Projects. New Jersey: John Wiley \& Sons, 2004.

BLICHFELDT, B. S.; ESKEROD, P. Project portfolio management - There's more to it than what management enacts. International Journal of Project Management, v. 26, p. 357$365,2008$.

BOSSIDY, L.; CHARAN, R.; BURCK, C. Execution: The Discipline of Getting Things Done. New York: Crown Business, 2002.

BOUTINET, J. P. Psychologie des conduites a projet. Paris: Presses Universitaires de France, 2006.

CALLAHAN, K.; BROOKS, L. Essentials of strategic project management. New Jersey: John Wiley \& Sons, 2004.

COLlinS, J. Good To Great - Why Some Companies Make The Leap And Other's Don't. New York: HarperCollins Publishers Inc., 2001.

COOPER, R; EDGETT, S., KLEINSCHMIDT, E. Portfolio Management - Fundamental to New Product Success. Product Development Institute: Working Paper n. 12, 2001 a.

COOPER, R, EDGETT, S., KLEINSCHMIDT, E. Portfolio Management of New Product Development: results of an industry. Practices, study. R\&D Management. Oxford, n. 31, $2001 b$.

DIETRICH, P.; LEHTONEN, P. Successful management of strategic intentions through multiple projects - reflections from empirical study. International Journal of Project Management, v. 23, n. 5, p. 386-391, 2005.

GIL, A. C. Métodos e técnicas de pesquisa social. São Paulo: Atlas, 2006.

GOVINDARAJAN, V.; TRIMBLE, C. The Other Side of Innovation: Solving the Execution Challenge. Boston: Harvard Business Press, 2010.

HREBINIAK, L. G. Making Strategy Work: Leading Effective Execution and Change. Wharton School Publishing. New Jersey: Pearson Prentice Hall, 2005.

IMPA [INTENATIONAL PROJECT MANAGEMENT ASSOCIATION], ICB - IPMA Competence Baseline, Version 3.0. Nijkerk: Internationam Project Managemet Association, 2006. 
JAMIESON, A.; MORRIS P. W. G. Moving from corporate strategy to project strategy. . In: MORRIS, P.W.G.; PINTO, J.K. (Ed,). The Wiley Guide to Managing Projects. New Jersey: John Wiley \& Sons, 2004.

JUGDEV, K.; THOMAS, J; DELISLE, C. L. Rethinking Project Management: old truths and new insights. International Project Management Journal, v. 7, n. 1, 2001.

KAPLAN, R. S.; NORTON, D. P. The Balanced Scorecard: Measures that Drive Performance. Boston: Harvard Business Review, 1992.

KAPLAN, R. S.; NORTON, D. P. The Execution Premium: Linking Strategy to Operations for Competitive Advantage. Boston: Harvard Business Press, 2008.

KAPlAN, R. S.; NORTON, D. P. Translating Strategy into Action, The Balanced Scorecard. Boston: Harvard Business Press, 1996.

KATHURIA, R.; JOSHI, M. P.; PORTH, S. J. Organizational alignment and performance: past, present and future. Management Decisison, v. 45, n.3, p.503-517, 2007.

KENDALL, G.; ROLLINS, S. Advanced project portfolio management and the PMO: Multiplying ROI at warp speed. Fort Lauderdale: Ross Publishing Inc, 2003.

KERZNER, H. Applied Project Management Best Practices on Implementation. New Jersey: John Wiley \& Sons, 2000.

KERZNER, H. Project Management: A Systems Approach to Planning, Scheduling, and Controlling, 10th. ed. New Jersey: John Wiley \& Sons, 2009.

LEVINE, H. A. Project portfolio management: A practical guide to selecting projects, managing portfolios, and maximizing benefits. San Francisco: Jossey-Bass, 2005.

MARTINSUO, M.; LEHTONEN, P. Role of single-project management in achieving portfolio management efficiency. International Journal of Project Management, v. 25, n.1 p. 56-65, 2007.

MAXIMIANO, A. C. A; RABECHINI. R. Maturidade em Gestão de Projetos - Análise de um Caso e Proposição de um Modelo. In: SIMPÓSIO DE GESTÃO DA INOVAÇÃO TECNOLÓGICA, Salvador, Bahia, 6 a 8 de novembro de 2002.

MILLER, J. A proven project portfolio management process. Proceedings of the Project Management Institute Annual Seminars \& Symposium, p. 347-352, 2002.

MINTZBERG, H. Rise and Fall of Strategic Planning. New York: The Free Press. 1994.

MINTZBERG, H., AHLSTRAND, B., LAMPEL, J. Safári de Estratégia: um roteiro pela selva do planejamento estratégico. Porto Alegre: Bookland. 2000.

OGC (OFFICE OF GOVERNMENT COMMERCE), Portfolio Management Guide. London: Office of Government Commerce, 2008.

PFEFFER, J.; SUTTON, R. I. The Knowing-Doing Gap: How Smart Companies Turn Knowledge into Action. Boston: Harvard Business School Press. 2000.

PINTO, J. K. Project Management 2001. Research Technology Management, v. 45, n. 2, p. 22-37, 2002.

PMI [PROJECT MANAGEMENT INSTITUTE]. Organizational project management maturity model (OPM3). Pennsylvania: Project Management Institute, 2006.

PMI [PROJECT MANAGEMENT INSTITUTE]. Standard of Portfolio Management. 2. ed. Pennsylvania: Project Management Institute, 2008. 
PRIETO, V. C.; CARVALHO, M. M.; FISCHMANN, A. A. Análise comparativa de modelos de alinhamento estratégico. Produção, v. 19, n. 2, p. 317-331, 2009.

RAD, P., RAGHAVAN, A. Establishing an Organizational Project Office. In: AACE International Transactions, pPM13, 2000.

SANCHEZ, H.; ROBERT, B.; PELLERIN, R. A Project Portfolio Risk-Opportunity Identification Framework. Project Management Journal, v. 39, n. 3, p. 97-109, 2008.

SHENHAR, A. Strategic project management: the new framework. Proceedings of the Portland International Conference on Management of Engineering and Technology. PICMET, Portland (OR), v. 2, p. 382-386, 1999.

SHENHAR, A.; DVIR, D. Reinventando Gerenciamento de Projetos: a abordagem diamante ao crescimento e inovação bem-sucedidos. São Paulo: M. Books, 2010.

SRIVANNABOON S.; MILOSEVIC D. Z. The process of translating business strategy in project actions. Innovations Project Management Research. Newtown Square, PA: Project Management Institute; 2004.

SRIVANNABOON, S. Linking project management with business strategy. Project Management Journal, v. 37, n. 5, p. 88-96, dez. 2006. 